\title{
Translation and Validation: Chinese Version of the HIV-Related Social Support Scale
}

\author{
Tiansheng Xie $\mathbb{D}^{1,2}$ \\ Haibo Yan $^{3}$ \\ Guohua Wang ${ }^{4}$ \\ 'Zhejiang Sino-German Institute of Life \\ science and Healthcare, School of \\ Biological and Chemical Engineering, \\ Zhejiang University of Science and \\ Technology, Hangzhou, Zhejiang, 310023. \\ People's Republic of China; ${ }^{2}$ State Key \\ Laboratory for Diagnosis and Treatment \\ of Infectious Diseases, The First Affiliated \\ Hospital of Zhejiang University, School of \\ Medicine, Zhejiang University, Hangzhou, \\ Zhejiang, 310003, People's Republic of \\ China; ${ }^{3}$ Center for Disease Prevention \\ and Control, Shaoxing, 3/2030, People's \\ Republic of China; ${ }^{4}$ Center for Disease \\ Prevention and Control, Jiaxing, 314500, \\ People's Republic of China
}

Purpose: Social support is increasingly recognized to be important in care of people living with HIV/AIDS (PLWH), we firstly translate and validate the disease-targeted social support instrument in Chinese and to explore the correlation with WHOQOL-HIV.

Patients and Methods: We established content validity for HIV-related social support scale (HSSS) and administered the resultant questionnaire to 310 PLWH. Descriptive statistics were generated for each of the variables of general characteristics; student $t$-test was used to compare the different groups.

Results: The HSSS demonstrated a high level of internal consistency, both within each subscale and with the total score; all Cronbach's $\alpha$ values exceeded a priori threshold of $\geq 0.70$. The HSSS cores were positively correlated with WHOQOL-HIV total scores (Pearson correlation: $0.39, P<0.001)$. We also found that higher educational level, personal income, CD4 cell count, and shorter duration of antiretroviral therapy are significantly associated with a higher level of social support $(P<0.05)$.

Conclusion: Social support may improve quality of life for PLWH, Chinese version of HIVrelated social support scale can be used in future clinical practice.

Keywords: HIV, AIDS, quality of life, social support

\section{Introduction}

HIV/AIDS has become an important public health issue. In China, about 958 thousand people were living with HIV/AIDS at the end of October 2019, and the number of HIV new infections is increasing from 60 thousand in 2008 to 140 thousand in $2018 .^{1,2}$ The global expansion of antiretroviral therapy (ART) provides real hope of long-term survival of HIV-infected individuals and had a great impact on HIV control in China. ${ }^{3-5}$ HIV may now be considered as a chronic disease, with greater long-term survival necessitating attention to the functional status and mental health. ${ }^{6,7}$ Therefore, it is important that mental and physical health needs be evaluated and that tailored interventions to address these needs be implemented to maximize the benefit of ART and improve overall health.

More and more studies focus on the psychological status of them. ${ }^{8-11}$ Social support was related to psychological distress and health. And increased social support serves to decrease mood disturbance during major life stress, and greater satisfaction with social support is associated with positive psychological states in PLWH. ${ }^{12,13}$ Low perceived social support has been shown to be associated with suboptimal ART adherence and attrition from care. ${ }^{14-17}$ Self-report instruments are simple way to assess mental and physical health. Many of the HIV-specific self-report tools assessing health-related quality of life (QOL) in HIV-infected patients, including the WHOQOL-HIV, ${ }^{18-20}$ were

Correspondence: Tiansheng Xie Zhejiang Sino-German Institute of Life science and Healthcare, School of Biological and Chemical Engineering, Zhejiang University of Science and Technology, 318 Liuhe Road, Hangzhou, Zhejiang Province, 310023, People's

Republic of China

Tel +8657l 86021350

Email tianshengxie@zust.edu.cn 
developed and utilized in developed countries, and the WHOQOL-HIV is available in a validated Chinese translation but does not include social supports. ${ }^{21}$ The purpose of this study was sought to translate and validate the first diseasetargeted social support scale instrument in Chinese. And analysis correlation of the psychometric properties of the HSSS and WHOQOL-HIV, among HIV-infected adults in China, try to know the reliability of these scales differed across groups defined by education, personal income, CD4 cell count or ART duration.

\section{Methods}

\section{Study Setting and Subjects}

We conducted a cross-sectional study in Zhejiang Province, where reported the first case of HIV in China in 1984, and the HIV epidemic entered a rapid growth period here until 2000. There were reported 32,918 HIV infections at the end of 2020, while the infection level in the whole of China was still low. ${ }^{22,23}$ Using convenience sampling we chose 310 patients selected from six counties in Zhejiang. All patients in the study met these inclusion criteria: confirmed HIV infection resulting from sexual transmission, age between 18 and 70 years, intellectual and psychological capacity to complete the investigation, absence of severe somatic symptoms.

\section{Ethical Review}

The study was complied with the Declaration of Helsinki and approved by the Ethics Committee of The First Affiliated Hospital at the School of Medicine of Zhejiang University. All the patients who were asked to participate in the study accepted and consented to participate, there were informed as to the purpose of the study.

\section{Investigation Contents}

Patients were asked about demographic and clinical characteristics, also completed the HSSS and WHOQOL-HIV questionnaires.

\section{General Information}

The general patient characteristics included age, gender, educational level, marital status, personal income, CD4 cell count, time since diagnosis, duration of ART.

\section{HSSS}

We measured social support using a newly translated instrument with 4 scales and 8 items in each scale. Scale 1, family support was defined as the receipt of emotional comfort from family members, Scale 2, work support was regarded as the influencing change from the workplace or colleague and also included self-report of the patient's ability to work, Scale 3, medical support meant health care from hospitals or other medical units, together with concern with the state of the patient's illness, Scale 4, social support focused on general support from the external environment or the patient's interaction with his or her social groups such as nongovernmental organizations. Summary scores were computed from each scale and analyzed as continuous variables.

\section{WHOQOL-HIV}

The WHOQOL-HIV is a self-reported questionnaire used to measure the QOL by seven subscales. General health status is evaluated by asking the subject to rate his or her health on the scale, which ranges from very poor (1) to very good (5). The structure of the WHOQOL-HIV includes a profile with scores across six domains (physical, psychological, level of dependence, social relationships, environment and spirituality) and 29 facets, of which 5 relate to HIV/AIDS (symptoms, social inclusion, forgiveness and blame, concerns about the future, death and dying).

\section{Data Collection and Analysis}

After receiving appropriate training offered by the lead researchers in this study, the physicians in each participating country began to conduct interviews. All data collected by paper-and-pencil surveys were input manually into a custom-designed database and analyzed using SPSS for Windows Version 16.0. Descriptive statistics were generated for each of the variables for general characteristics, the scores of the HSSS and sub-scale were represented as mean $\pm \mathrm{SD}$, the reliability was calculated by using Cronbach's method, also used Student $t$-tests and correlation analysis to compare the different groups to the HSSS. Values of $P<0.05$ were considered statistically significant.

\section{Results}

\section{Demographic and Clinical Characteristics}

We interviewed 310 patients. Of these 212 (68.40\%) were male, and the mean age was $44.48 \pm 12.06$ years. About twothirds were married or cohabiting, 126 (40.90\%) cases had received at most 6 years of education, and half of them had annual personal income less than 2000 RMB. The median duration of HIV infection was 4 years, with the SD value 2.79 years, and the mean CD4 count was $340.59 \pm 157.96$. The mean ART duration was $2.16 \pm 1.69$ years (Table 1 ). 
Table I Patient Demographics and Clinical Characteristics

\begin{tabular}{|l|c|}
\hline Items & $\mathbf{N}=\mathbf{3} 1 \mathbf{0}$ \\
\hline Age(years),mean(SD) & $44.48(12.06)$ \\
Gender (male) (\%) & $68.40 \%$ \\
Married or cohabiting (\%) & $67.10 \%$ \\
\hline Education & \\
6 years or less N (\%) & $126(40.90 \%)$ \\
Over 6 years N (\%) & $182(59.10 \%)$ \\
\hline Personal income (lyears) & \\
2000 RMB or less N (\%) & $156(50.30 \%)$ \\
Over 2000 RMB N (\%) & $154(49.70 \%)$ \\
CD4 count(mean) (SD) & $340.59(157.96)$ \\
ART duration years mean(SD) & $2.16(1.69)$ \\
\hline
\end{tabular}

Abbreviations: SD, standard deviation; ART, antiretroviral therapy; RMB, China yuan.

\section{Reliability of HSSS}

The HSSS demonstrated a high level of internal consistency, both within each subscale and with the overall higher-order scale. Table 2 provides the Cronbach's $\alpha$ for each domain. All Cronbach's $\alpha$ values exceeded our a priori threshold of $\geq 0.70$, indicating that all of the subscales performed well together as a composite measure.

\section{Correlations Among Scales}

As hypothesized, HSSS scores were positively correlated with WHOQOL-HIV total scores (Pearson correlation: 0.39, $P<$ 0.01; Table 3), physical health scores (Pearson correlation: $0.29, P<0.01$ ), psychological scores (Pearson correlation: 0.34, $P<0.01$ ), social scores (Pearson correlation: $0.26, P<$ 0.01 ), religion scores (Pearson correlation: $0.42, P<0.01$ ), and general health scores (Pearson correlation: 0.27, $P<0.01$ ). Also, subscales of the HSSS show correlations to the difference scale of the WHOQOL-HIV. The HSSS family scale was positively correlated with physical health scores, psychological scores and general health scores (Pearson correlation ranged from 0.18 to 0.22 ); the HSSS work scale was positively

Table 2 Numbers of Items, Mean Score, and Reliability of the HSSS

\begin{tabular}{|l|c|l|r|}
\hline Scale & $\begin{array}{c}\text { Numbers of } \\
\text { Item }\end{array}$ & $\begin{array}{l}\text { Mean } \\
\text { Score(SD) }\end{array}$ & $\begin{array}{r}\text { Cronbach's } \\
\boldsymbol{\alpha}\end{array}$ \\
\hline Family & 8 & $25.77 \pm 4.33$ & 0.78 \\
Work & 8 & $24.59 \pm 4.05$ & 0.83 \\
Medical & 8 & $26.20 \pm 4.64$ & 0.81 \\
Social & 8 & $22.56 \pm 2.87$ & 0.72 \\
Total & 32 & $99.12 \pm 11.14$ & 0.88 \\
\hline
\end{tabular}

Abbreviation: SD, standard deviation.
Table 3 Pearson Correlations Between HSSS and WHOQOLHIV Subscale

\begin{tabular}{|l|l|l|l|l|l|}
\hline Subscale & Family & Work & Medical & Social & $\begin{array}{l}\text { Total- } \\
\text { HSSS }\end{array}$ \\
\hline Physical & $0.22^{* *}$ & 0.15 & $0.36^{* *}$ & 0 & $0.29 * *$ \\
Psychological & $0.2^{*}$ & $0.28^{* *}$ & $0.32^{* *}$ & 0.09 & $0.34^{* *}$ \\
Independence & 0.02 & 0.04 & $0.21^{* *}$ & $-0.17^{*}$ & 0.06 \\
Social & 0.1 & $0.36^{* *}$ & $0.18^{*}$ & 0.06 & $0.26^{* *}$ \\
Environment & 0.09 & $0.17^{*}$ & 0.14 & -0.08 & 0.13 \\
Religion & 0.21 & $0.32^{* *}$ & $0.48^{* *}$ & 0.08 & $0.42^{* *}$ \\
General health & $0.18^{*}$ & $0.25^{* *}$ & $0.21^{* *}$ & 0.08 & $0.27^{* *}$ \\
Total-QOL & $0.22^{* *}$ & $0.33^{* *}$ & $0.45^{* *}$ & 0 & $0.39 * *$ \\
\hline
\end{tabular}

Notes: $* P<0.05 ; * * P<0.01$

Abbreviation: $\mathrm{QOL}$, quality of life.

correlated with psychological scores, social scores, environment scores, religion scores, and general health scores (Pearson correlation ranged from 0.17 to 0.36 ); the HSSS medical scale was positively correlated with physical health scores, psychological scores, independence scores, social scores, religion scores, and general health scores (Pearson correlation ranged from 0.18 to 0.48 ); by contrast, the HSSS social scale was only negatively correlated with independence scores (Pearson correlation: 0.17, $P<0.05$ ).

\section{Factors Associated with Difference Scale in HSSS Measures}

The HSSS score in the group that received at most 6 years of education was significantly lower than in the group with more than 6 years $(P<0.01)$, the same trends can be seen in all subscales. Also, the HSSS score in the group with annual personal income less than 2000 RMB was significantly lower than that in the group with more than 2000 RMB annually $(P<0.01)$, and the same trends can be seen in all subscales, especially the family, work and social scales $(P=0.006,0.018$ and 0.031 , respectively). We found that compared with the group with lower CD4 count, the group with higher CD4 count had a higher score on the HSSS $(P=0.01)$, especially in the work subscale $(P=0.02)$. The HSSS score in the group with ART duration of 1 year or less was higher than that in the group with over 1 year, and the variation in medical and social subscales was significant $(P=0.019$ and 0.009 , respectively). (Table 4, Figure 1)

\section{Discussion}

This is, to our knowledge, the first published analysis of the reliability and construct validity of scales to measure social 
Table 4 Student's t-test of the HSSS Scores in Different Groups

\begin{tabular}{|l|c|c|c|}
\hline Items & Mean & SD & $P$ value \\
\hline Education & & & $p<0.05$ \\
6 years or less & 96.71 & 9.16 & \\
Over 6 years & 100.74 & 12.15 & \\
\hline Personal income (lyears) & & & $p<0.05$ \\
2000 RMB or less & 97.71 & 7.95 & \\
Over 2000 RMB & 100.56 & 13.54 & \\
\hline CD4 count (/mL) & & & $p<0.05$ \\
200 cells or less & 99.00 & 14.94 & \\
More than 200 cells & 99.15 & 10.33 & \\
\hline ART duration & \multicolumn{3}{|l}{} \\
I year or less & 100.41 & 11.59 & 0.25 \\
Over I year & 98.09 & 10.73 & \\
\hline
\end{tabular}

Abbreviation: SD, standard deviation.

support in an adult HIV-infected population in China. Its subscales focus especially on the most relevant 4 fields: work, family, medical and social. We found that the HSSS performed well in the study population: the scales demonstrated good reliability, as indicated by a Cronbach's $\alpha$ coefficient of 0.88 for the entire cohort, as well as across subscales, where $\alpha$ values ranged from 0.72 to 0.83 .

In keeping with our hypotheses, we found that the scales correlated with each other in expected directions: social support was positively correlated with QOL and its subscales except the independence and environment subscales. Discrimination related to HIV/AIDS is the most commonly reported problem faced by PLWH. ${ }^{24}$ The family support subscale is positively correlated with the physical and psychological subscales of QOL; in fact, the fear that family members will face stigma can overshadow even personal stigma. ${ }^{25,26}$ In China when a person becomes HIV-positive, they are considered to have brought shame to their family. ${ }^{27,28}$ The work support subscale is positively correlated with the psychological, social and religion subscales, and the medical support subscale is positively correlated with all QOL subscales except the environment subscale. Some researchers have attributed the negative attitudes of medical staff to insufficient knowledge about the disease and concerns about their own safety. ${ }^{29}$ The social subscale is negatively correlated with all QOL subscales except the independence subscale. Associations between the physical health score and clinical markers of HIV disease also support the scale's construct validity.
We also found participants who received significantly lower social support, especially as measured by family and social support subscales. Subjects with lower personal income received significantly less social support as shown on all subscales except the medical subscale. Their low level of education, poor economic conditions, lack of social support, diverse cultural backgrounds, unhealthy behavior and habits, and lack of knowledge and understanding regarding transmission of HIV/AIDS may negatively impact their capacity to deal with their disease. AIDS-related education, as provided by public organizations, emphasizes understanding, caring, and support for PLWH, which may encourage PLWH to face their situations. ${ }^{27,30}$ Experiencing psychological distress while living in poverty may lead to a variety of adjustment difficulties and limit the participants' ability to receive care. ${ }^{31}$ Also, a lower CD4 cell count usually is correlated with lower social support especially on the work subscale, and patients' level of social support, especially on the medical and social subscales, tended to decrease, the longer they had been receiving ART.

Several limitations of this study should be noted. The patient sample was from only one coastal province in China, where the primary transmission of HIV/AIDS was unprotected sex. Thus, the findings may not be representative of PLWH in other geographic areas within the country or of persons infected through another route of transmission. Also, about $41 \%$ of the subjects had no more than 6 years of education from the study may also have altered the findings. In common with other studies using self-report instruments, the researcher had to assume that the respondents were truthful and fully understood the questions being asked. Further predictive and intervention studies are necessary to determine the predictors of psychological status and social support in this and other populations in China.

\section{Conclusion}

The findings in this study support the reliability and construct validity of the HSSS scale in PLWH in China. With this validated tool, clinicians and researchers can identify risk factors for inadequate social support and study how these conditions may lead to adverse HIV-related outcomes in China. This standardized tool may also be used to identify subgroups that would benefit from interventions that aim to interrupt the relationship between these risk factors and adverse health outcomes, thereby improving public health in China, where HIV-related physical and psychological are both prevalent and disruptive. 

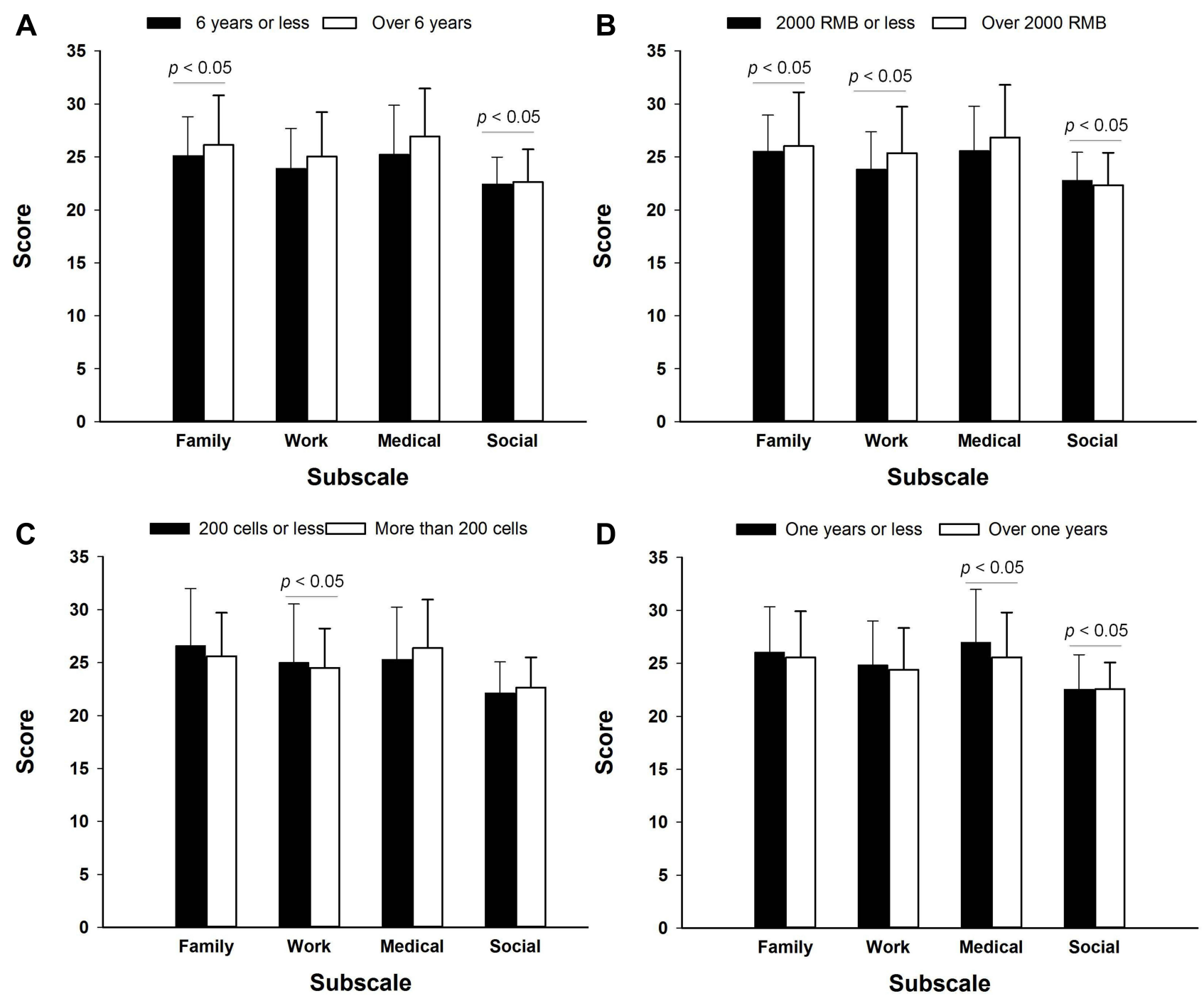

Figure I Comparison of scale scores in different items. (A) Comparison of scale scores in different education group, (B) Comparison of scale scores in different annual personal income group, (C) Comparison of scale scores in different CD4 count group, (D) Comparison of scale scores in different ART duration group.

\section{Data Sharing Statement}

The authors are willing to share the entire individual participant data collected during the study, after deidentification. These data will be available beginning 3 months and ending 5 years after article publication. Requests should be directed to tianshengxie@126.com. To gain access, data requestors are needed to sign a data access agreement.

\section{Acknowledgments}

We thank the Health Bureau of Zhejiang Province for providing all necessary assistance.

\section{Funding}

This study was supported by the National Natural Science Foundation of China (No.81602943), and the Mega-
Project for National Science and Technology Development (2017ZX10105001). The founders had no role in study design, data collection and analysis, decision to publish, or preparation of the manuscript.

\section{Disclosure}

The authors report no conflicts of interest in this work.

\section{References}

1. World Health Organization. Latest HIV estimates and updates on HIV policies uptake, November 2020. World Health Organization; 2020. Available from: https://www.who.int/docs/default-source/hiv-hq/latest-hivestimates-and-updates-on-hiv-policies-uptake-november2020.pdf?sfvrsn= 10a0043d 12. Accessed May 1, 2021.

2. Joint United Nations Program on HIV/AIDS (UNAIDS). Progress towards the 90-90-90 targets ending AIDS. UNAIDS; 2017. Available from: https://www.unaids.org/sites/default/files/media asset/Global_AIDS_update_2017_en.pdf. Accessed May 1, 2021. 
3. Shao Y, Jia Z. Challenges and opportunities for HIV/AIDS control in China. Lancet. 2012;379(9818):804. doi:10.1016/S0140-6736(12) 60349-3

4. Zhang F, Dou Z, Ma Y, et al. Effect of earlier initiation of antiretroviral treatment and increased treatment coverage on HIV-related mortality in China: a National Observational Cohort Study. Lancet Infect Dis. 2011;11(7):516-524. doi:10.1016/S1473-3099(11)70097-4

5. Zhang F, Dou Z, Yu L, et al. The effect of highly active antiretroviral therapy on mortality among HIV-infected former plasma donors in China. Clin Infect Dis. 2008;47(6):825-833. doi:10.1086/590945

6. Cohen MS, Chen YQ, McCauley M, et al. Prevention of HIV-1 infection with early antiretroviral therapy. $N$ Engl J Med. 2011;365 (6):493-505. doi:10.1056/NEJMoa1105243

7. Long EF, Brandeau ML, Owens DK. The cost-effectiveness and population outcomes of expanded HIV screening and antiretroviral treatment in the United States. Ann Intern Med. 2010;153 (12):778-789. doi:10.7326/0003-4819-153-12-201012210-0 0004

8. Haighton C, Moffatt S, Howel D, et al. The Do-Well Study: protocol for a randomised controlled trial, economic and qualitative process evaluations of domiciliary welfare rights advice for socio-economically disadvantaged older people recruited via primary health care. BMC Public Health. 2012;12(1):382. doi:10.1186/1471-2458-12-382

9. Casale M, Wild L, Cluver L, Kuo C. The relationship between social support and anxiety among caregivers of children in HIV-endemic South Africa. Psychol Health Med. 2014;19(4):490-503. doi:10.1080/13548506.2013.832780

10. Phillips JC, Webel A, Rose CD, et al. Associations between the legal context of HIV, perceived social capital, and HIV antiretroviral adherence in North America. BMC Public Health. 2013;13(1):736. doi:10.1186/1471-2458-13-736

11. Szaflarski M. Spirituality and religion among HIV-infected individuals. Curr HIV/AIDS Rep. 2013;10(4):324-332. doi:10.1007/ s11904-013-0175-7

12. Forouzan AS, Jorjoran Shushtari Z, Sajjadi H, Salimi Y, Dejman M. Social support network among people living with HIV/AIDS in Iran. AIDS Res Treat. 2013;2013:715381. doi:10.1155/2013/ 715381

13. Oppong Asante K. Social support and the psychological wellbeing of people living with HIV/AIDS in Ghana. Afr $J$ Psychiatry (Johannesbg). 2012;15(5):340-345. doi:10.4314/ajpsy.v15i5.42

14. Delvaux T, Elul B, Ndagije F, Munyana E, Roberfroid D, Asiimwe A. Determinants of nonadherence to a single-dose nevirapine regimen for the prevention of mother-to-child HIV transmission in Rwanda. J Acquir Immune Defic Syndr. 2009;50(2):223-230. doi:10.1097/ QAI.0b013e31819001a3

15. Vissman AT, Young AM, Wilkin AM, Rhodes SD. Correlates of HAART adherence among immigrant Latinos in the Southeastern United States. AIDS Care. 2013;25(3):356-363. doi:10.1080/ 09540121.2012.701722

16. Starks H, Simoni J, Zhao H, et al. Conceptualizing antiretroviral adherence in Beijing, China. AIDS Care. 2008;20(6):607-614. doi: 10.1080/09540120701660379
17. Wang $\mathrm{X}, \mathrm{Wu} \mathrm{Z}$. Factors associated with adherence to antiretroviral therapy among HIV/AIDS patients in rural China. AIDS. 2007;21 (Suppl 8):S149-155. doi:10.1097/01.aids.0000304711.87164.99

18. O'Connell KA, Skevington SM. An international quality of life instrument to assess wellbeing in adults who are HIV-positive: a short form of the WHOQOL-HIV (31 items). AIDS Behav. 2012;16(2):452-460. doi:10.1007/s10461-010-9863-0

19. Saddki N, Noor MM, Norbanee TH, et al. Validity and reliability of the Malay version of WHOQOL-HIV BREF in patients with HIV infection. AIDS Care. 2009;21(10):1271-1278. doi:10.1080/ 09540120902803216

20. Sheng Y, Qiu Z-Q, He Y, Juniper N, Zhang Y. Living conditions and palliative care needs among end-of-life former commercial plasma donors affected with HIV/AIDS in rural Henan of China. Biomed Environ Sci. 2010;23(4):279-286. doi:10.1016/S0895-3988(10)60064-5

21. da Silva J, Bunn K, Bertoni RF, Neves OA, Traebert J. Quality of life of people living with HIV. AIDS Care. 2013;25(1):71-76. doi:10.1080/09540121.2012.686594

22. Zhejiang Provincial Bureau of Statistics. Zhejiang Statistical Yearbook 2020. China Statistics Press; 2020.

23. Bureau of Health of Zhejiang Province. Zhejiang province reported the latest HIV/AIDS epidemic; 2020. Available from: https://zj.zjol. com.cn/news/1570731.html. Accessed July 20, 2021.

24. Sun H, Zhang J, Fu X. Psychological status, coping, and social support of people living with HIV/AIDS in central China. Public Health Nurs. 2007;24(2):132-140. doi:10.1111/j.1525-1446.2007.00617.x

25. Ramaswamy M, Kelly PJ, Li X, Berg KM, Litwin AH, Arnsten JH. Social support networks and primary care use by HIV-infected drug users. J Assoc Nurses AIDS Care. 2013;24(2):135-144. doi:10.1016/ j.jana.2012.05.001

26. Slater LZ, Moneyham L, Vance DE, Raper JL, Mugavero MJ, Childs G. Support, stigma, health, coping, and quality of life in older gay men with HIV. J Assoc Nurses AIDS Care. 2013;24 (1):38-49. doi:10.1016/j.jana.2012.02.006

27. Yu Y, Li X, Zhang L, et al. Domestic chores workload and depressive symptoms among children affected by HIV/AIDS in China. AIDS Care. 2013;25(5):632-639. doi:10.1080/09540121.2012.722603

28. Zhao G, Li X, Fang X, et al. Functions and sources of perceived social support among children affected by HIV/AIDS in China. AIDS Care. 2011;23(6):671-679. doi:10.1080/09540121.2010.525619

29. Li X, Zhang L, Stanton B, Fang X, Xiong Q, Lin D. HIV/AIDSrelated sexual risk behaviors among rural residents in China: potential role of rural-to-urban migration. AIDS Educ Prev. 2007;19 (5):396-407. doi:10.1521/aeap.2007.19.5.396

30. White K, Rudolph AE, Jones KC, et al. Social and individual risk determinants of HIV testing practices among noninjection drug users at high risk for HIV/AIDS. AIDS Care. 2013;25(2):230-238. doi:10.1080/09540121.2012.701269

31. Sun W, Wu M, Qu P, Lu C, Wang L, Loutfy MR. Quality of life of people living with HIV/AIDS under the new epidemic characteristics in China and the associated factors. PLoS One. 2013;8(5):e64562. doi:10.1371/journal.pone. 0064562
International Journal of General Medicine

\section{Publish your work in this journal}

The International Journal of General Medicine is an international, peer-reviewed open-access journal that focuses on general and internal medicine, pathogenesis, epidemiology, diagnosis, monitoring and treatment protocols. The journal is characterized by the rapid reporting of reviews, original research and clinical studies

\section{Dovepress}

across all disease areas. The manuscript management system is completely online and includes a very quick and fair peer-review system, which is all easy to use. Visit http://www.dovepress.com/ testimonials.php to read real quotes from published authors. 